Evanston Hospital, Division of

Gastroenterology, Evanston, Ilinois, USA R I Breuer

Evanston Hospital, Department of Pathology M L Christ

Froedtert Memorial Lutheran Hospital, Division of Gastroenterology,
Milwaukee, Wisconsin, USA

K H Soergel

Cleveland Clinic

Foundation,

Department of

Gastroenterology,

Cleveland, Ohio, USA

B A Lashner

University of Chicago Hospital, Section of Gospital, Section of Gastroenterology, S B Hanauer

Northwestern Memorial Hospital, Division of Gastroenterology, Chicago, Illinois, USA A Vanagunas

University of Illinois at Chicago, Department of Medicine, Chicago, Illinois, USA

J M Harig

Loyola University Medical Centre Section of Gastroenterology, Maywood, Illinois, USA

A Keshavarzian

Oklahoma Foundation for Digestive Research, Oklahoma City, Oklahoma, USA M Robinson

The University of Texas Health/Science Centre at Houston, Division of

Gastroenterology, Houston, Texas, USA

J H Sellin

Digestive Health Care, Minneapolis,

Minnesota, USA

D Weinberg

Rockford Gastroenterology Centre, Rockford, Illinois, USA D E Vidican

Evanston Hospital, Special GI Laboratory, K L Flema

Northwestern University Medical School, Department of Preventive Medicine, Chicago, Illinois, USA A W Rademaker

Correspondence to: Dr Richard I Breuer, Evanston Hospital, Special GI Laboratory, 2650 Ridge Avenue, Evanston, IL 60201, USA.

Accepted for publication 28 November 1996

\title{
Short chain fatty acid rectal irrigation for left-sided ulcerative colitis: a randomised, placebo controlled trial
}

\author{
R I Breuer, K H Soergel, B A Lashner, M L Christ, S B Hanauer, A Vanagunas, \\ J M Harig, A Keshavarzian, M Robinson, J H Sellin, D Weinberg, D E Vidican, \\ K L Flemal, A W Rademaker
}

\begin{abstract}
.
Background-Short chain fatty acid (SCFA) deficiency is associated with colitis in animals and humans, and the mucosal metabolism of these compounds is decreased in ulcerative colitis.

Aims-To assess the efficacy of topical SCFA treatment in ulcerative colitis.

Patients and Methods-103 patients with distal ulcerative colitis were entered into a six week, double-blind, placebo controlled trial of rectal SCFA twice daily; patients who were unchanged on placebo were offered SCFA in an open-label extension trial.
\end{abstract}

Results-Of the 91 patients completing the trial, more patients in the SCFA treated than in the placebo treated group improved $(33 \% v 20 \%, p=0 \cdot 14, N S)$. Those on SCFA also had larger, but statistically non-significant, reductions in every component of their clinical and histological activity scores. In patients with a relatively short current episode of colitis (<6 months, $n=42$ ), more responded to SCFA than to placebo $(48 \%$ v $18 \%$, $\mathbf{p}=0 \cdot 03)$. These patients also had larger, but statistically non-significant, decreases in their clinical activity index $(p=0.08 v$ placebo). Every patient who improved used at least five of six of the prescribed rectal SCFA irrigations, whereas only $37 \%$ who did not improve were as compliant. In the open-label extension trial, $65 \%$ improved on SCFA; these patients also had significant reductions $(p<0.02)$ in their clinical and histological activity scores.

Conclusions-Although SCFA enemas were not of therapeutic value in this controlled trial, the results suggest efficacy in subsets of patients with distal ulcerative colitis including those with short active episodes. Prolonged contact with rectal mucosa seems to be necessary for therapeutic benefit.

(Gut 1997; 40: 485-491)

Keywords: short chain fatty acids, distal ulcerative colitis.

Treatment of distal ulcerative colitis consists mainly of topical or oral 5-aminosalicylic acid (5-ASA) compounds or corticosteroids, or both. These compounds alter the inflamma- tory response by decreasing oxygen free radical activity and proinflammatory cytokine release, and by modifying the lipo- and cyclooxygenase pathways of arachidonic acid metabolism. ${ }^{1}$ They are relatively expensive, not uniformly effective, are not free of undesired systemic effects even in their new formulations, ${ }^{2}$ and repeated treatment courses are often needed. Short chain fatty acids (SCFA) have been proposed as an inexpensive alternative topical treatment for distal ulcerative colitis. ${ }^{3}$ Acetate, propionate and butyrate are the predominant ions in faecal water ${ }^{4}$ and provide most of the metabolic energy for normal colonic epithelial cells. ${ }^{5}$ When SCFA are completely absent, diversion colitis develops in humans and experimental animals. ${ }^{6}$ Decreased colonic SCFA concentrations resulting from suppression of the bacterial flora may contribute to antibiotic associated diarrhoea. ${ }^{8}$ Butyrate oxidation by colonocytes is impaired in active and quiescent ulcerative colitis. ${ }^{9}$ This may be an intrinsic metabolic defect, or it may be the result of increased luminal concentrations of sulphites, sulphides and mercaptans produced by sulphate reducing bacteria in ulcerative colitis. ${ }^{10}$ In a preliminary trial, nine of 11 patients treated for six weeks with SCFA rectal irrigations showed clinical, endoscopical and histological improvement. ${ }^{3}$ We now report the results of a randomised, double-blind, placebo controlled study, and of an open-label trial of SCFA rectal irrigation in those patients who did not respond to placebo.

\section{Methods}

A diagnosis of distal ulcerative colitis was established by standard clinical, endoscopical and histological criteria. For inclusion, symptoms must have appeared at least three months prior to entry and disease had to extend from at least $15 \mathrm{~cm}$ to no more than 65 $\mathrm{cm}$ from the anal verge. At entry, patients must have been on either no medication or stable doses of oral 5-ASA or corticosteroids $(\leq 30 \mathrm{mg}$ prednisolone per day), or both, for at least six weeks, and off rectal corticosteroids for at least one month and rectal mesalazine for at least one week. Oral medication was maintained without dosage change throughout the study. Patients less than 18 years of age, those with clinically important hepatic or renal disease and pregnant women were excluded. Flexible 
sigmoidoscopy was performed routinely on entry; colonoscopy was required if it had not been performed within the previous year to confirm the absence of proximal disease. Stool frequency, rectal bleeding and endoscopical appearance were each rated on a scale from 0 (normal) to 3 (notably abnormal) for each. ${ }^{11} \mathrm{~A}$ scale for impact of disease on activities of daily living was added: $0=$ no effect, $1=$ minor effect or interference, $2=$ major effect on some aspects, $3=$ unable to participate in usual activity. The sum of these scores (maximum=12) was termed the disease activity index (DAI). To enter, patients had to have a DAI of at least 4 . Without knowledge of treatment status biopsy specimens obtained from the same area before and after the trial were graded on a scale from 0 to 3 for each of the following criteria: cryptitis/abscesses, surface erosions/exudates, polymorphonuclear leucocytes in the lamina propria, and glandular mucin depletion. The sum of these scores (maximum=12) was termed the histology index. Laboratory studies obtained within one week of entry and at the end of the six week study period included complete blood count, electrolytes, multichemistry panel, urinalysis, and stools for ova and parasites and Clostridium difficile toxin. A 48 hour stool collection was obtained before and after the trial with the patients following their self-selected diets. The stools were refrigerated during the collection period and kept frozen at $-20^{\circ} \mathrm{C}$ pending analysis. Short chain fatty acids were extracted from faecal fluid and measured by gas chromatography. ${ }^{12}$

Assignment to placebo or SCFA rectal enema was by a separate table of random assignment prepared for each of the nine participating centres. Treatment consisted of $100 \mathrm{ml}$ enemas given upon rising and at bedtime for six weeks. Patients were encouraged to retain the enemas as long as possible. SCFA enemas contained sodium acetate $(80 \mathrm{mmol} / \mathrm{l})$, sodium propionate $(30$ $\mathrm{mmol} / \mathrm{l})$ and sodium butyrate $(40 \mathrm{mmol} / \mathrm{l})$ adjusted to $\mathrm{pH} 7$ with $1 \mathrm{~N} \mathrm{NaOH}$. Placebo enemas consisted of $\mathrm{NaCl}(140 \mathrm{mmol} / \mathrm{l})$ also adjusted to $\mathrm{pH} 7$. Patients were contacted by telephone at one and two weeks and evaluated in person at the end of the third week. The study was terminated if the patient or study physician concluded that the course of the disease had worsened. At the end of the trial, flexible sigmoidoscopy was repeated and the DAI recalculated. In addition, the managing physician and the patient, both unaware of treatment modality, conjointly assessed and agreed upon a global result as follows: complete remission, much improved, minimally improved, no change, or worse. Treatment response was defined as complete remission/much improved, unless stated otherwise. Pre- and post-treatment biopsy specimens were evaluated by the study pathologist who was unaware of the clinical status. Patients kept a daily diary to record symptoms (number of bowel movements, bleeding and abdominal pain), and use and retention of study enemas. For those who did not improve, the code was broken immediately after the final evaluation. Placebo treated patients in this group were offered SCFA enemas in a six week, open-label extension trial, using the same protocol as described earlier. Protocols were approved by the Institutional Review Board of each participating institution, and all patients gave informed consent.

In the double-blind study, baseline comparisons of treatment groups were performed using the $\chi^{2}$ test or the two sample $t$ test. ${ }^{13}$ Global assessment was compared between treatment groups using the Mantel-Haenszel test adjusting for centre. ${ }^{13}$ Changes in DAI score, histology score and their components were compared between treatment groups using analysis of covariance, adjusting for centre. $^{14}$ Changes in DAI scores, histology scores and their components were compared between baseline and follow up (for both the double-blind and open-label studies) using the paired $t$ test. ${ }^{13}$ Faecal SCFA were correlated with DAI using Pearson's correlation coefficient. ${ }^{13}$ Changes in disease activity and histology scores were compared between the double-blind and open-label studies using the paired $t$ test. An interim analysis was performed after 41 patients had been entered. ${ }^{15}$ The purpose of this interim analysis was to estimate treatment differences and to update the initial calculations of statistical power. Therefore, no adjustment to the criterion for significance is made in the final analyses. A sample size of 45 analysable patients per group had $80 \%$ power to detect a mean difference of 1.8 in DAI change between the active treatment and control groups. Statistical significance is indicated when $p<0 \cdot 05$. All tests were two-tailed.

In assessing outcome, no adjustment for covariates other than clinical centre were made for three reasons. First, there were no statistically significant differences between the SCFA and placebo groups for any baseline covariate. Second, although some covariates were observed to be related to change in disease status as measured by a global response (see Results), these relations were seen only in one of the two study groups. Third, none of these covariates altered the conclusions regarding treatment effect - that is, only minimal changes to the $p$ values for treatment occurred when they were adjusted for.

The baseline characteristics in Table I were related to global response separately for the SCFA and placebo groups using Fisher's exact test and the two sample $t$ test. $^{13}$ A multiple logistic regression analysis was used to assess the independent effects of factors found significant at the $5 \%$ level. ${ }^{14}$ Logistic regression analysis with an interaction term was used to determine whether a factor significantly altered the SCFA treatment effect as measured by global assessment. ${ }^{14}$

\section{Results}

One hundred and three patients from nine centres entered the trial: 53 received placebo and 50 the SCFA enemas. Baseline 
TABLE I Baseline characteristics of patients treated with $S C F A$ or placebo in the double-blind trial

\begin{tabular}{|c|c|c|}
\hline Characteristic & $S C F A$ & Placebo \\
\hline 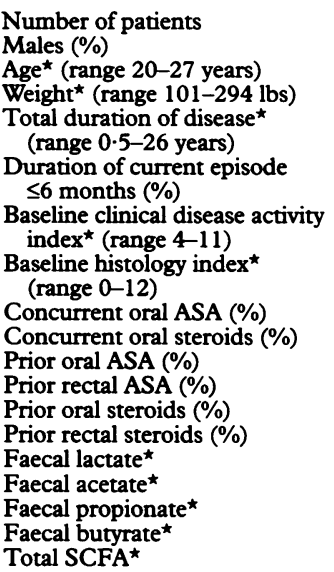 & $\begin{array}{l}7 \cdot 93(1 \cdot 73) \\
5.93(2 \cdot 71) \\
36 \\
18 \\
44 \\
51 \\
33 \\
49 \\
5 \cdot 5(9 \cdot 0) \\
54 \cdot 2(31 \cdot 3) \\
17 \cdot 7(10 \cdot 6) \\
13 \cdot 5(9 \cdot 0) \\
87 \cdot 0(47 \cdot 7)\end{array}$ & $\begin{array}{l}7 \cdot 51(1 \cdot 93) \\
5 \cdot 10(2 \cdot 72) \\
45 \\
19 \\
40 \\
59 \\
29 \\
48 \\
3 \cdot 8(4 \cdot 2) \\
55 \cdot 1(29 \cdot 9) \\
16 \cdot 3(10 \cdot 9) \\
16 \cdot 0(12 \cdot 7) \\
88 \cdot 7(49 \cdot 0)\end{array}$ \\
\hline
\end{tabular}

${ }^{\star}$ Mean (SD).

characteristics were similar with no significant differences between the two groups (Table I). Three patients (all SCFA) who never returned for evaluation were not considered further. Of the remaining 100, nine were judged unanalysable (two SCFA, seven placebo): five could not take or were unable to retain more than a few enemas, three had major protocol violations, and one developed a non-gastrointestinal disease requiring corticosteroid therapy. Of the remaining 91 analysable patients, 46 had been assigned to the placebo group and 45 to SCFA treatment. Inclusion of the nine unanalysable patients in the analysis (intention to treat) did not change the statistical conclusions reported here.

TABLE II Distribution of clinical global assessment at end of the six week double-blind trial

\begin{tabular}{lllllll}
\hline & $\begin{array}{l}\text { Complete } \\
\text { remission }\end{array}$ & $\begin{array}{l}\text { Much } \\
\text { improved }\end{array}$ & $\begin{array}{l}\text { Minimally } \\
\text { improved }\end{array}$ & $\begin{array}{l}\text { No } \\
\text { change }\end{array}$ & Worse \\
\hline SCFA $(\mathrm{n}=45)$ & 4 & 11 & 3 & 22 & 5 \\
Placebo $(\mathrm{n}=46)$ & 1 & 8 & 6 & 25 & 6 \\
\hline
\end{tabular}

Complete remission +much improved + minimally improved $=$ $18 / 45(40 \%) v 15 / 46(33 \%), p=0.44$ by Mantel-Haenszel test. $95 \%$ Confidence interval for difference $-13 \%$ to $27 \%$. Complete remission+much improved $=15 / 45(33 \%) v 9 / 46$ $(20 \%), p=0 \cdot 14$ by Mantel-Haenszel test. $95 \%$ Confidence interval for difference $-5 \%$ to $31 \%$.

TABLE III Change from baseline in DAI and histology scores after treatment with either $S C F A$ or placebo in the double-blind trial

\begin{tabular}{|c|c|c|c|c|c|c|}
\hline Score & $S C F A^{\star}$ & $p$ value & Placebo* & $p$ valuet & $p$ value $\ddagger$ & $95 \% C I$ \\
\hline $\begin{array}{l}\text { Clinical DAI } \\
\text { Range }\end{array}$ & $\begin{array}{l}-2.05(0.53) \\
-9 \text { to } 4\end{array}$ & 0.0004 & $\begin{array}{l}-1 \cdot 19(0 \cdot 42) \\
-7 \text { to } 4\end{array}$ & 0.007 & 0.23 & $-0 \cdot 49,2 \cdot 21$ \\
\hline $\begin{array}{l}\text { Stool frequency } \\
\text { Rectal bleeding } \\
\text { Mucosal appearance } \\
\text { Impact on lifestyle } \\
\text { Histology index } \\
\text { Range }\end{array}$ & $\begin{array}{l}-0.38(0.18) \\
-0.76(0.17) \\
-0.52(0.16) \\
-0.38(0.13) \\
-0.37(0.45) \\
-7 \text { to } 6\end{array}$ & $\begin{array}{l}0.04 \\
0.0001 \\
0.002 \\
0.005 \\
\text { NS }\end{array}$ & $\begin{array}{l}-0.14(0.11) \\
-0.40(0.15) \\
-0.37(0.13) \\
-0.37(0.14) \\
0.69(0.62) \\
-7 \text { to } 9\end{array}$ & $\begin{array}{l}\text { NS } \\
0.01 \\
0.04 \\
0.01 \\
\text { NS }\end{array}$ & $\begin{array}{l}0.30 \\
0 \cdot 11 \\
0 \cdot 29 \\
0 \cdot 88 \\
0 \cdot 19\end{array}$ & $\begin{array}{l}-0.18,0.66 \\
-0.08,0.80 \\
-0.18,0.66 \\
-0.39,0.37 \\
-2.57,0.45\end{array}$ \\
\hline $\begin{array}{l}\text { Erosions/exudates } \\
\text { Cryptitis/abscesses } \\
\text { Segmented leucocytes } \\
\text { Mucin depletion }\end{array}$ & $\begin{array}{r}-0.10(0.18) \\
-0.10(0.18) \\
0.20(0.15) \\
-0.37(0.18)\end{array}$ & $\begin{array}{l}\text { NS } \\
\text { NS } \\
\text { NS } \\
0.05\end{array}$ & $\begin{array}{l}0.14(0.21) \\
0.13(0.20) \\
0.12(0.16) \\
0.30(0.21)\end{array}$ & $\begin{array}{l}\text { NS } \\
\text { NS } \\
\text { NS } \\
\text { NS }\end{array}$ & $\begin{array}{l}0.34 \\
0.38 \\
0.66 \\
0.03\end{array}$ & $\begin{array}{l}-0 \cdot 79,0.31 \\
-0.76,0 \cdot 30 \\
-0.30,0.52 \\
-1 \cdot 22,-0.12\end{array}$ \\
\hline
\end{tabular}

*Mean (SEM).

tp values by paired $t$ test comparing pre- with post-treatment scores within each group. $\neq \mathrm{p}$ values by analysis of covariance comparing pre- to post-treatment changes between the two

$\mathrm{CI}=$ confidence interval.
The distribution of global assessments at the end of the six week trial is shown in Table II. More SCFA treated patients (40\%) showed some improvement (complete remission/much improved/minimally improved) than those randomised to placebo $(33 \%, \mathrm{p}=0.44, \mathrm{NS})$. This difference was greater when we considered substantial improvement only (complete remission/much improved) as treatment response $(33 \% \vee 20 \%, \mathrm{p}=0 \cdot 14, \mathrm{NS})$. Within both the SCFA and placebo groups, except for stool frequency in the latter, the scores for each component and the composite DAI improved significantly between the beginning and the end of the study (Table III). Although SCFA treated patients improved more in each measurement and the decrease in the DAI was almost twice that for placebo, none of the differences in the pre- to post-treatment changes between the groups was statistically significant. The mean total histology score for SCFA treated patients improved slightly during the trial, whereas that for the placebo group worsened (Table III); neither trend was statistically significant. For SCFA treated patients, there was some minor improvement in three of four components of that score ( $p=0.05$ for mucin depletion), whereas for placebo treated patients, all components showed some deterioration ( $p=N S$ for each). For mucin depletion, the difference in pre- to post-treatment change between SCFA and placebo treated patients was statistically significant $(p=0.03)$.

To determine whether any baseline characteristic influenced outcome, we evaluated the relation between each factor in Table I and treatment response. Short duration of current colitis attack ( $\leq 6$ months), baseline disease activity and sex were related to global response in the SCFA group only (Table IV). Multiple logistic regression analysis indicated that all three factors contributed independently to response - that is, each was significant $(p<0.05)$ in the model with all three factors. However, on direct comparison between SCFA and placebo treated patients within each subgroup, only short duration of current colitis attack seemed to influence treatment outcome significantly (Table IV).

Responses to prior medications were available in only about two-thirds of our study group. Among these, only 33\% of those who had tried rectal 5-ASA and $34 \%$ of those who had tried rectal steroids had ever responded to these medications.

Compliance with the enema protocol was poor. Only $28(62 \%)$ of 45 SCFA and 32 $(70 \%)$ of 46 placebo treated patients completed five weeks ( 35 days) or more of the trial and retained more than half of the enemas for at least 30 minutes. In the SCFA treated group, every patient who improved (complete remission/much improved/minimally improved) compared with only $37 \%$ of those who did not improve was compliant by these criteria. Among all analysable patients who completed at least 35 days of the trial, there was a trend towards more SCFA than placebo treated patients showing treatment response 
TABLE IV Subgroup comparison of response as measured by global assessment (clinical remission + much improved) after treatment with SCFA or placebo in the double-blind trial

\begin{tabular}{|c|c|c|c|c|c|c|}
\hline \multirow[b]{2}{*}{ Factor } & \multicolumn{2}{|c|}{$S C F A$} & \multicolumn{2}{|c|}{ Placebo } & \multirow[b]{2}{*}{ p value } & \multirow[b]{2}{*}{$\begin{array}{l}\text { SCFA-placebo } \\
\text { difference }\end{array}$} \\
\hline & $n$ & $\%$ & $n$ & $\%$ & & \\
\hline \multicolumn{7}{|c|}{ Duration of current episode } \\
\hline $\begin{array}{r}<6 \text { months } \\
>6 \text { months } \\
\text { Baseline DAI }\end{array}$ & $\begin{array}{l}25 \\
20\end{array}$ & $\begin{array}{l}48 \\
15(0.03) \ddagger\end{array}$ & $\begin{array}{l}17 \\
29\end{array}$ & $\begin{array}{l}18 \\
21(0.99) \ddagger\end{array}$ & $\begin{array}{l}0 \cdot 03^{\star} \\
0.51^{\star}\end{array}$ & $\begin{array}{l}30 \% \\
-6 \%(0.045) \dagger\end{array}$ \\
\hline $\begin{array}{l}<7 \\
>7\end{array}$ & $\begin{array}{l}20 \\
25\end{array}$ & $\begin{array}{l}10 \\
52(0.004) \ddagger\end{array}$ & $\begin{array}{l}22 \\
24\end{array}$ & ${ }_{29}^{9}(0 \cdot 14) t$ & $\begin{array}{l}0 \cdot 78^{\star} \\
0 \cdot 10^{\star}\end{array}$ & $1 \%$ \\
\hline \multicolumn{7}{|r|}{$23 \%(0.09) \dagger$} \\
\hline $\begin{array}{l}\text { Female } \\
\text { Male }\end{array}$ & $\begin{array}{l}17 \\
28\end{array}$ & $\begin{array}{l}59 \\
18(0.008) \ddagger\end{array}$ & $\begin{array}{l}19 \\
27\end{array}$ & $\begin{array}{l}26 \\
15(0 \cdot 46) \ddagger\end{array}$ & $\begin{array}{l}0.06^{\star} \\
0.75^{\star}\end{array}$ & $\begin{array}{l}33 \% \\
3 \%(0.28) \dagger\end{array}$ \\
\hline
\end{tabular}

* $\mathrm{p}$ values by Mantel-Haenszel test comparing SCFA with placebo subgroups for each factor. tp values by logistic regression for interaction comparing differences between SCFA and placebo groups for each factor.

$\ddagger \mathrm{p}$ values comparing per cent response between subgroups within SCFA and placebo groups for each factor by Fisher's exact test.

(15 (44\%) of $24 v$ eight $(22 \%)$ of $36, p=0 \cdot 07)$. In this group of compliant patients, the DAI also tended to improve more in those on SCFA than those on placebo $(\Delta=-2.65 v-1 \cdot 25$, $\mathrm{p}=0.09$ ).

No significant side effects were detected by physical examination or laboratory results. The only reported side effect was occasional minor anal irritation caused by the enema tip. Mean (SEM) initial faecal SCFA concentrations (Table I) were lower than those reported previously for normal subjects (acetate, 83 (9) $\mathrm{mmol} / \mathrm{l}$; propionate, 21 (2) $\mathrm{mmol} / \mathrm{l}$; butyrate, 21 (3) $\mathrm{mmol} / \mathrm{l}),{ }^{11}$ below those in our irrigation solution and did not differ between SCFA and placebo groups. Conversely, faecal lactate concentrations were higher than normal $(<1$ $\mathrm{mmol} / \mathrm{l}$ ) in both groups. ${ }^{15}$ At baseline, for the entire study cohort, the DAI correlated inversely with initial faecal propionate, butyrate and total SCFA $(\mathrm{r}=-0.32, \mathrm{p}=0.004$; $r=-0.22, p=0.05 ; r=-0.23, p=0.04$, respectively) and directly with faecal lactate $(r=0 \cdot 21$,

TABLE V Distribution of clinical global assessment of patients at end of open-label extension trial

\begin{tabular}{lll}
\hline & $n$ & $\%$ \\
\hline Complete remission & 4 & 24 \\
Much improved & 4 & 24 \\
Minimally improved & 3 & 18 \\
No change & 6 & 35
\end{tabular}

Complete remission+much improved + minimally

improved $=11 / 17(65 \%) .95 \%$ Confidence interval $42-88 \%$.

Complete remission + much improved $=8 / 17(47 \%) .95 \%$

Confidence interval $23-71 \%$. TABLE VI Clinical and histology scores before and after six weeks of treatment with SCFA
in the open-label extension trial

\begin{tabular}{|c|c|c|c|c|c|}
\hline Score & Before ${ }^{\star}$ & After* & $\Delta^{\star}$ & $p \dagger$ & $95 \% C I$ \\
\hline $\begin{array}{l}\text { Clinical DAI }(n=15) \\
\text { Range }\end{array}$ & $\begin{array}{l}7 \cdot 60(0 \cdot 24) \\
6 \text { to } 9\end{array}$ & $\begin{array}{l}4 \cdot 33(0 \cdot 73) \\
0 \text { to } 8\end{array}$ & $\begin{array}{l}-3 \cdot 27(0 \cdot 81) \\
-1 \text { to } 9\end{array}$ & 0.001 & -5.01 to -1.53 \\
\hline Stool frequency & $2 \cdot 13(0.17)$ & $1.40(0.25)$ & $-0.73(0.32)$ & 0.04 & -1.42 to -0.04 \\
\hline Rectal bleeding & $1.47(0 \cdot 19)$ & $0 \cdot 87(0 \cdot 19)$ & $-0.60(0.24)$ & 0.02 & -1.12 to -0.08 \\
\hline $\begin{array}{l}\text { Mucosal appearance } \\
\text { Impact on lifestyle }\end{array}$ & $\begin{array}{l}2.53(0.13) \\
1.47(0.19)\end{array}$ & $\begin{array}{l}1.53(0.31) \\
0.53(0.13)\end{array}$ & $\begin{array}{l}-1.00(0.29) \\
-0.93(0.21)\end{array}$ & 0.004 & $\begin{array}{l}-1.62 \text { to }-0.38 \\
-1.38 \text { to }-0.48\end{array}$ \\
\hline $\begin{array}{l}\text { Histology index }(n=14) \\
\text { Range }\end{array}$ & $\begin{array}{l}6 \cdot 79(0 \cdot 72) \\
2 \text { to } 11\end{array}$ & $\begin{array}{l}4 \cdot 36(0 \cdot 84) \\
0 \text { to } 9\end{array}$ & $\begin{array}{l}-0.93(0.21) \\
-2.43(0.51) \\
-2 \text { to } 6\end{array}$ & $\begin{array}{l}0.0005 \\
0.0004\end{array}$ & $\begin{array}{l}-1.38 \text { to }-0.48 \\
-3.53 \text { to }-1.33\end{array}$ \\
\hline Erosions/exudates & $0.93(0.27)$ & $0.86(0.27)$ & $-0.07(0.27)$ & $0 \cdot 79$ & -0.65 to 0.51 \\
\hline Cryptitis/abscesses & $2.00(0.21)$ & $1.14(0.23)$ & $-0.86(0.21)$ & 0.001 & -1.31 to -0.41 \\
\hline $\begin{array}{l}\text { Segmented leucocytes } \\
\text { Mucin depletion }\end{array}$ & $1 \cdot 71(0 \cdot 19)$ & $1.36(0.20)$ & $-0.36(0.20)$ & $0 \cdot 10$ & -0.78 to 0.07 \\
\hline Mucin depletion & $2 \cdot 14(0 \cdot 25)$ & $1.00(0.28)$ & $-1 \cdot 14(0 \cdot 25)$ & 0.001 & -1.68 to -0.60 \\
\hline
\end{tabular}

^Mean (SEM)

tp value by paired $t$ test.

$\mathrm{CI}=$ confidence interval. $p=0 \cdot 05)$. At the end of the study, improvement in DAI correlated with a decrease in faecal lactate $(r=0 \cdot 30, p=0 \cdot 01)$. The concentrations of each faecal SCFA increased but none of the correlations was significant.

OPEN-LABEL TRIAL IN PLACEBO

NON-RESPONDERS

Seventeen patients who had not improved on placebo during the double-blind study opted for six weeks of SCFA solution in the openlabel trial. Eleven (65\%) showed some improvement (complete remission/much improved/minimally improved), of whom eight $(47 \%)$ were either much improved or in clinical, including endoscopical, remission (Table V). After six weeks of SCFA enemas, their mean DAI score and scores for each component of that index improved significantly (Table VI). Their histology indexes also improved by the six week end point (Table VI). Figure 1 shows the components of their DAI responses and Figure 2 the components of their histology index responses to SCFA in the extension trial compared with those to placebo in the double-blind trial. By each clinical and histological measurement, these patients improved more on SCFA than during the preceding placebo period. Many differences were statistically significant. All patients who improved for whom compliance data were available (nine of 11) were compliant as defined above.

\section{Discussion}

Short chain fatty acids are the preferred energy source of colonic epithelial cells, especially those in the distal colon and rectum. ${ }^{5}$ Although patients with distal ulcerative colitis may have increased, ${ }^{16}$ normal or only moderately decreased stool SCFA concentrations compared with normal subjects, ${ }^{11}$ their colonocytes do not use these compounds readily. ${ }^{9} \mathrm{We}$ and others have postulated that increased concentrations of, or prolonged contact with, SCFA might have a therapeutic effect in ulcerative colitis by overcoming a metabolic defect, enhancing cell repair or by some other mechanism. ${ }^{3}{ }^{18}{ }^{19}$ Although a controlled trial of nightly butyrate enemas failed to show benefit, ${ }^{20}$ several uncontrolled ${ }^{31921}$ and controlled clinical trials ${ }^{1822-24}$ using enemas twice daily have suggested that rectal instillation of these compounds may be helpful in the management of patients with distal ulcerative colitis.

In our original design, we projected a $60 \%$ clinical response rate for SCFA and a $30 \%$ response rate for placebo in order to have an $80 \%$ chance of showing statistical significance. By these criteria, the results of this doubleblind, placebo controlled trial do not show a definite benefit for SCFA in the treatment of distal ulcerative colitis. However, all trends in the blinded trial were in favour of SCFA. The significant response of those with a relatively short current episode of colitis to SCFA in our trial and the results of the open-label follow up 


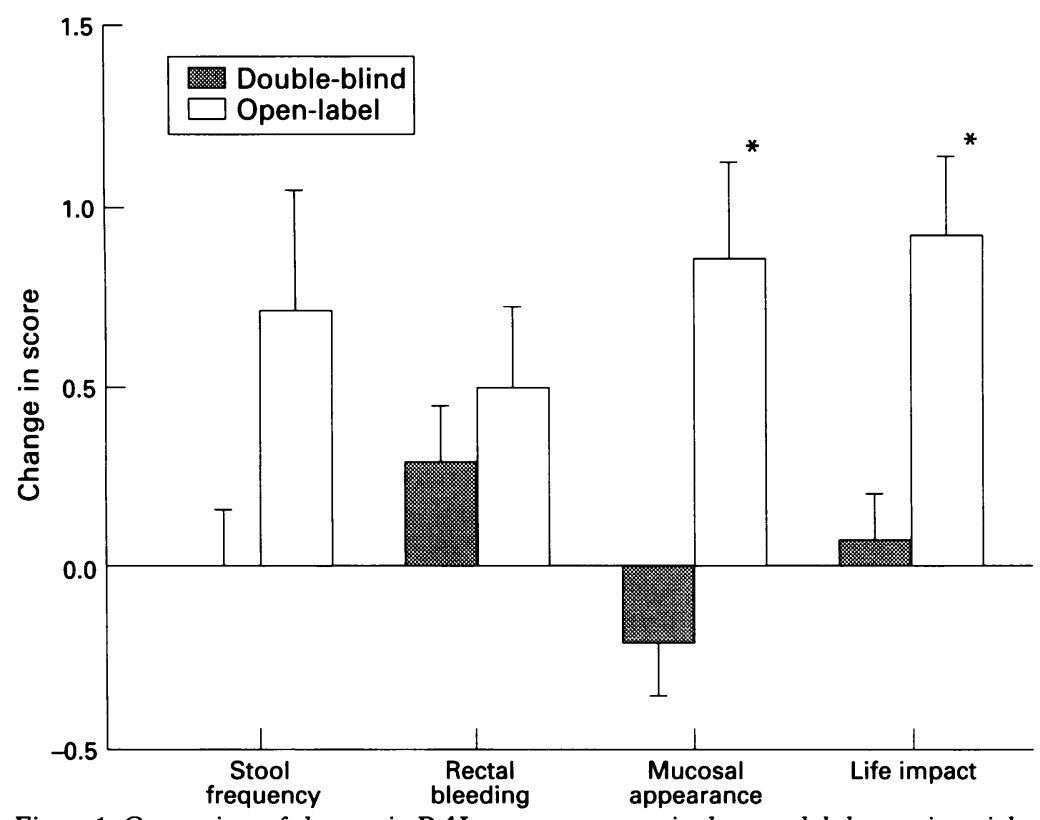

Figure 1: Comparison of changes in DAI component scores in the open-label extension trial with those for the same patients in the double-blind trial $(n=14)$. A positive change indicates improvement, a negative change indicates worsening. Columns are mean (SEM). ${ }^{\star} p=0.01$ by paired $\mathrm{t}$ test, double-blind $\mathrm{v}$ open-label extension trial.

trial suggest that certain subsets of patients will improve or enter remission. Therefore, we examined our data to determine why fewer than the expected number of patients responded to SCFA in the double-blind study.

Many of our patients were very or at least moderately ill: on our 12 point DAI scale, $20 \%$ had scores $\geq 10$ and more than two-thirds were $\geq 7$. Twenty per cent required steroids as maintenance medication on entry. The nonsignificant trend toward a better response rate in those with a DAI $\geq 7$ suggests this was not a major factor. Many patients entered into our trial may have had a particularly refractory type of distal colitis; during prior episodes of active

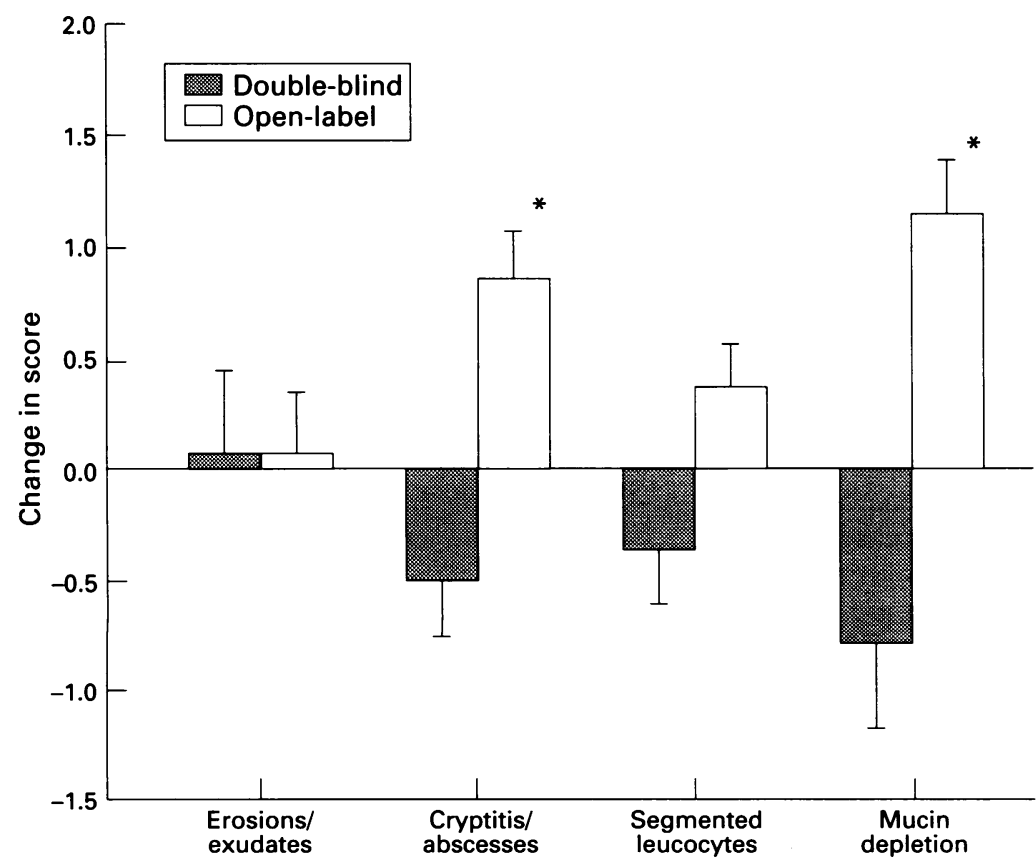

Figure 2: Comparison of changes in histology index component scores in the open-label extension trial with those for the same patients in the double-blind trial $(n=14)$. A positive change indicates improvement, a negative change indicates worsening. Columns are mean $(S E M) .{ }^{\star} p=0.002$ by paired $\mathrm{t}$ test, double-blind $\mathrm{v}$ open-label extension trial. disease, their responses to standard rectal medications had been about half those usually reported. ${ }^{1125}$ For some patients, this trial was the last step before colectomy; others, especially those from tertiary care centres, were veterans of clinical trials whose symptoms had been refractory to medical therapy for years.

Compliance with the protocol may be another factor. Although overall compliance was poor, every SCFA treated patient who improved completed at least 35 of the 42 days of the trial and retained more than half the enemas for at least 30 minutes compared with a minority of those SCFA treated patients who did not improve. Poor compliance occurred despite frequent contact with the subjects as required by the study protocol, and was not statistically different between patients in the placebo and SCFA groups. Reasons given included travel and inability to retain the enemas. Interestingly, the odour of butyrate was not recorded as a factor affecting compliance. Whether taking five of six of the prescribed treatments and enema retention time depended on disease severity, early improvement, motivation or other factors is not clear. However, these data suggest that increased mucosa-SCFA contact time may be an important determinant of efficacy.

Finally, we used a mixture of SCFA corresponding approximately to physiological concentrations of acetate and propionate and double that for butyrate, whereas other investigators have used butyrate alone. Positive blinded studies by Senegore $e t a l^{23}$ and Vernia et $a^{22}$ using the same or similar mixture as ours and the comparable results for the mixture and butyrate alone in one trial suggest that the composition of the SCFA solution was not a major factor. $^{24}$

Vernia et al reported positive results in a placebo controlled trial in 40 patients with "mild to moderately severe" colitis by the Truelove-Witts' criteria ${ }^{26}$ using a design similar to ours and the same SCFA rectal irrigation solution. ${ }^{22}$ None of their patients required steroids at entry and most seemed to have a milder form of colitis than those in our trial. In addition, all the Italian patients were on maintenance 5-ASA during the six week trial compared with only $37 \%$ of our study cohort. These investigators have suggested that rectal SCFA may be more effective in patients receiving 5-ASA concomitantly because of proposed different modes of action.

The results of our follow up, open-label study in which two-thirds of placebo nonresponders in the double-blind trial improved on rectal SCFA and a half improved notably (complete remission/much improved) suggest that the effect of our rectal solution is SCFA related and not due to a non-specific washout effect of noxious substances such as lactate ${ }^{3}$ or reduced sulphate compounds. ${ }^{10}$ These patients' notable improvement in the endoscopical appearance of the affected mucosa as well as in their histology scores document the potential for SCFA related healing in some patients. 
SCFA rectal irrigation seems to be safe. In addition to the 67 patients treated with rectal SCFA in this trial, we know of nine other trials in which SCFA rectal irrigations have been given to 130 additional patients with colitis without any reported side effect (Breuer RI, unpublished data). ${ }^{318-24}$ Four trials used a SCFA mixture identical or similar to ours, four butyrate alone and one compared the SCFA mixture with butyrate; four were open-label, four were double-blind, and four had concurrent comparison or control groups. Differences in study design and patient populations make comparison of results difficult. Overall, more than two-thirds of patients improved and a trend favouring SCFA was observed in all studies except the one that used a single rather than twice daily rectal instillation, ${ }^{20}$ illustrating the need for prolonged mucosa-SCFA contact.

The mechanism(s) by which SCFA may influence the clinical course, and endoscopical and histological findings in ulcerative colitis are complex and best studied for butyrate. Preliminary evidence from our laboratory suggests that butyrate oxidation by colonocytes from patients with ulcerative colitis does not increase in a concentration dependent manner on exposure to up to $100 \mathrm{mM}$ butyrate, well above that in our irrigation solution (Pollack J and Breuer RI, 1995, unpublished data). However, the responses of colonocytes to butyrate or mixtures of SCFA at the luminal $\mathrm{pH}$ and high concentrations of reduced sulphur compounds present in colitis have not been studied. ${ }^{10}$ Butyrate also plays a key part in mucosal repair processes, reduces mucosal permeability ${ }^{19}$ and facilitates salt and water absorption. ${ }^{27}$ These effects may, in turn, reduce bleeding, favour healing of colitis, reduce mucosal transmigration of bacterial or food antigens, and diminish diarrhoea. Butyrate also stimulates proliferation of normal colon cells, ${ }^{18}$ dilates resistance arteries of the colon increasing blood flow and mucosal oxygen uptake,$^{28}$ reduces upper crypt labelling frequency, improves the differentiation of cell lines from normal and neoplastic tissues, ${ }^{27}$ and acts as an anti-neoplastic agent. ${ }^{30}$ Thus, in addition to being a preferred nutritional substrate for colonocytes, butyrate seems to be an important intracellular modulator of many metabolic processes.

The significant correlation between high clinical activity scores and low faecal SCFA and high lactate values in this study confirms prior observations. ${ }^{12} 1517$ The correlation between decreased lactate and increased SCFA concentrations with clinical improvement does not clarify whether these changes are determinants or markers of clinical activity. The results of this double-blind, placebo controlled trial, though negative according to our initial study design, and especially the open-label follow up study suggest that a mixture of SCFA may be effective therapy in subsets of patients with distal ulcerative colitis. Except for those with short duration of current attack ( $<6$ months), we have not been able to identify definitely which subgroup of patients would be most likely to benefit. The data suggest that future studies that include patients with distal colitis with relatively short attack duration on maintenance 5-ASA may be most useful in evaluating the role of SCFA as a primary or adjunct treatment for distal ulcerative colitis. Prolonged contact of the SCFA mixture with the mucosal surface seems to be an important factor for clinical efficacy. Therefore, future study designs might include more frequent applications of the topical solution, formulating the enema to improve retention, use of a foam to increase contact time, providing SCFA in an oral encapsulated form designed for release in the inflamed area, or using a slowly fermented oral substrate such as fermented starch. ${ }^{31}$

This study was supported by grant number FDU-000553 from the Orphan Products Development Division of the Food and Drug Administration and also by grant EH90-048 from Evanston Hospital. Additional funding was received from Orphan Medical Inc, and Pharmascience Inc. We wish to thank the CB Fleet Company, Lynchburg, Virginia, USA, for supplying the enema bottles.

1 Podolsky DK. Inflammatory bowel disease (first of two parts). N Engl f Med 1991; 325: 928-35.

disease: Is it a magic bullet? N Engl f Med 1994; 331: 873-4.

3 Breuer RI, Buto SK, Christ ML, Bean J, Vernia $P$, Paoluzi P, et al. Rectal irrigation with short-chain fatty acids for distal ulcerative colitis: preliminary report. Dig Dis Sci 1991; 36: 185-7.

4 Rubinstein $\mathrm{R}$, Howard $\mathrm{AV}$, Wrong $\mathrm{OM}$. In vivo dialysis of faeces as a method of stool analysis: the organic anion component. Clin Sci 1969; 37: 549-64.

5 Roediger WEW. Utilization of nutrients by isolated epithelial cells of the rat colon. Gastroenterology 1982; 83: 424-9.

6 Harig JM, Soergel KH, Komorowski RA, Wood CM Treatment of diversion colitis with short-chain fatty acid irrigation. N Engl $\mathcal{F}$ Med 1989; 320: 23-8.

7 Kelli E, Bouchoucha M, Carnot F, Francoual GN, Calisse $\mathrm{D}$, Chourrout $\mathrm{Y}$, et al. Creation of an experimental model for the diversion colitis in rats [abstract]. Gastrointest Endosc 1992; 102: A644.

8 Clausen MR, Bonnen H, Tvede M, Mortensen PB. Colonic fermentation to short-chain fatty acids is decreased in antibiotic-associated diarrhea. Gastroenterology 1991; 101: $1497-504$.

9 Roediger WEW. The colonic epithelium in ulcerative colitis an energy-deficiency disease? Lancet 1980; ii: 712-5.

10 Roediger WEW, Duncan A, Kapaniris O, Millard S. Reducing sulfur compounds of the colon impair colonocyte nutrition: implications for ulcerative colitis. Gastroenterology 1993; 104: 802-9.

11 Sutherland LR, Martin F, Greer S, Robinson M, Greenberger N, Saibil F, et al. 5-aminosalicylic acid enema in the treatment of distal ulcerative colitis, proctosigmoiditis, and proctitis. Gastroenterology 1987; 92: $1894-8$.

12 Vernia P, Gnaedinger A, Hauck W, Breuer RI. Organic anions and the diarrhea of inflammatory bowel disease. Dig Dis Sci 1988; 33: 1353-8.

13 Daniel WW. Biostatistics: A foundation for analysis in the health sciences. 6th edn. New York: John Wiley, 1995.

14 Anderson S, Auquier A, Hauck WW, Oakes D, Vandaele W, Weisberg HI. Statistical methods for comparative studies: Techniques for bias reduction. New York: John Wiley, 1980

5 Breuer RI, Christ ML, Lashner BA, Soergel, KH, Hanauer $\mathrm{SB}$, Harig JM, et al. Short chain fatty acid rectal irrigation therapy for left-sided ulcerative colitis: a randomized, placebo-controlled clinical trial. Interim report. In: Binder HJ, Cummings J, Soergel KH, eds. Falk Symposium 73: Short chain fatty acids. Hingham: Kluwer Academic Publishers, 1994: 214-20.

16 Roediger WEW, Heyworth $M$, Willoughby P, Piris J, Moore A, Truelove SC. Luminal ions and short chain
fatty acids as markers of functional activity of the mucosa in ulcerative colitis. $\mathcal{F}$ Clin Pathol 1982; 35: 323-6.

17 Vernia P, Caprilli R, Latella G, Barbetti F, Magliocca FM, Cittadini M. Fecal lactate and ulcerative colitis. Gastroenterology 1988; 95: 1564-8.

18 Scheppach W, Sommer H, Kirchner T, Paganelli G, Bartram P, Christl S, et al. Effect of butyrate enemas on Bartram P, Christl $S$, et al. Effect of butyrate enemas on the colonic mucosa in dista

19 Vernia P, Cittadini M, Caprilli R, Torsoli A. Topical treatment of refractory distal ulcerative colitis with 5-ASA and sodium butyrate. Dig Dis Sci 1995; 40: 305-7. 
20 Steinhart AH, Hiruki T, Brzezinski A, Baker JP. Treatment of left-sided ulcerative colitis with butyrate enemas: a controlled trail. Aliment Pharmacol Ther 1996; 10: 729-36.

21 Steinhart AH, Brzezinski A, Baker JP. Treatment of refractory ulcerative proctosigmoiditis with butyrate refractory ulcerative proctosigmoiditis with

22 Vernia P, Marcheggiano A, Caprilli R, Frieri R, Corrao G Valpiani $\mathrm{D}$, et al. Short-chain fatty acid topical treatment in distal ulcerative colitis. Aliment Pharmacol Ther 1995; 9: 309-13.

23 Senagore AJ, MacKeigan JM, Scheider M, Ebrom S. Shortchain fatty acid enemas: a cost-effective alternative in the treatment of nonspecific proctosigmoiditis. Dis Colon Rectum 1992; 35: 923-7.

24 Scheppach WA. Are short chain fatty acids effective in the local treatment of ulcerative colitis [abstract]? Gastroenterology 1996; 110: A1010.

25 Danish 5-ASA Group. Topical 5-aminosalicylic acid versus prednisolone in ulcerative proctosigmoiditis. A randomized, double-blind multicenter trial. Dig Dis Sci 1987; 32: 598-602.
26 Truelove SC, Witts LJ. Cortisone in ulcerative colitis: a fina report on a therapeutic trial. $B M F$ 1955: 1041-8.

27 Ruppin H, Bar-Meir S, Soergel KH, Wood CM, Schmit MG Jr Absorption of short-chain fatty acids by the colon. Gastroenterology 1980; 78: 1500-7.

28 Mortensen FV, Nielsen H, Mulvany MJ, Hessov I. Short chain fatty acids dilate isolated human colonic resistance arteries. Gut 1990; 31: 1391-4.

29 Tanaka Y, Bush KK, Klauck TM. Enhancement of butyrate-induced differentiation of HT-29 human colon carcinoma cells by 1,25-dihydroxyvitamin D3. Biochem Pharmacol 1989; 38: 3859-65.

30 Kruh J, Defer N, Tichonicky L. Molecular and cellular effects of sodium butyrate. In: Roche AF, ed. Short-chain fatty acids: metabolism and clinical importance. Report of the 10th Ross Conference on medical research. Columbus: Ross Laboratories, 1991: 45-50.

31 Faisant N, Buleon A, Colonna P, Molis C, Lartigue S, Galmiche JP, et al. Digestion of raw banana starch in the small intestine of healthy humans: structural features of resistant starch. Br $\mathcal{F}$ Nutr 1995; 73: 111-23. 